\title{
Geodynamic interpretations of continent-scale hiatus maps in the Atlantic Realm
}

\author{
BERTA VILACÍS, JORGE N. HAYEK, HANS-PETER \\ BUNGE, ANKE M. FRIEDRICH, SARA CARENA AND \\ INGO L. STOTZ
}

Ludwig-Maximilians-Universität München

Presenting Author: bvilacis@geophysik.uni-muenchen.de

The South Atlantic has long been seen as the archetypical passive margin, where margin topography generated during the rifting process gives way to gradual post-rift subsidence controlled primarily by conductive cooling of the lithosphere. This view has been challenged by scenarios that allow for a more active margin evolution, honoring numerous observational constraints derived from individual studies as well as coordinated research efforts such as the DFG funded SAMPLE program and the French TOPO AFRICA program, all of which suggest that repeated uplift and subsidence episodes took place along the South American and African side of the basin. While active-passive margin scenarios are entirely consistent with geodynamic expectations informed by fluid dynamic considerations of highly vigorous sublithospheric mantle flow, it is likely that the underlying mantle convection processes operate on broader scales than passive margins. This view is based on mantle convection planform studies, sublithosphere seismic imaging, estimates of plate driving forces and other considerations. Here we report our recently published work on continent-scale hiatus mapping which - by extracting hiatus information in a single manipulation from existing interregionalscale geologic maps - allows us to visualize the distribution of major conformable and unconformable contacts at the level of geologic series across continents. Focusing on North/South America, Europe and Africa from the Upper Jurassic onward, and assuming that interregional hiatus surfaces are proxy records of continent-scale dynamic topography, we find significant differences in hiatus patterns across and between the continents bordering the Atlantic realm, with a particularly prominent Eocene event in South America. We find moreover that hiatus events take place at the timescale of geologic series, that is ten to a few tens of millions of years (Myrs). This is smaller than the mantle transit time, which, as the timescale of convection, is about 100-200 Myrs, implying that different timescales for convection and topography in convective support must be an integral component of time-dependent geodynamic Earth models. Our results call for intensified collaboration between geodynamicists and geologists to improve our understanding of interregional-scale geologic events. 